\title{
An Expert System for Advising to Buy a Football Player Using Visual Prolog
}

\author{
Mahdi Gholami mehr, Hossein Shirazi \\ Department of Computer and Information Technology, Malek-Ashtar University of Technology, Tehran, Iran \\ Email: Mahdi.Gholami.mehr@gmail.com, Shirazi@mut.ac.ir
}

Received May 11, 2012; revised June 25, 2012; accepted July 4, 2012

\begin{abstract}
This work presents the design of an Expert System that aims to advice the club teams to buy a football player in the post that they needed. Suggesting different player in many posts by an expert person is based on football experience, knowledge about the player and the club that he works. For mechanization the ability of this person, we use Expert System because it can model the ability of a person in solving a problem. Visual Prolog language is used as a tool for designing our Expert System.
\end{abstract}

Keywords: Artificial Intelligence; Expert System; Visual Prolog; Football Adviser

\section{Introduction}

Many real-world problems have no algorithmic solution or the use of these types of solutions required to respond in good time performance, ease of changing requirements, and there are uncertainties in the behavior of the system. However, the argument that people in solving problems such as advice to buy a football player, select the direction for tourism, and ...cannot see that disabled people are not dead-end computing. Among the ideas that are inspired by the human reasoning, are Neural Networks and Expert Systems "if-then" rules. Expert Systems for problems that do not have any specific algorithm, is the best solution. An Expert System is a system that employs human knowledge captured in a computer to solve problems that ordinarily require human expertise [1,2]. Expert System seeks and utilizes relevant information from their human users and from available knowledge bases in order to make recommendations [3]. With the Expert System, the user can interact with a computer to solve a certain problem. This can occur because the Expert System can store heuristic knowledge. The development of Expert System is implemented in Visual Prolog environment. This programming tool is designed for facilitate the development of software to model human knowledge.

In this article we want to show that why advice club team to buy a player, is important. Many club teams in the transfer season are looking for players that can help their team in the future season. Buying the player that has the condition of a club team is very important because a bad buy can have financial losses and the team cannot have success in the whole season. For example, if without any expertise buy a player that in the whole season is injured, the club team may have trouble in the post that this player is played. Therefore, a person who can have good advice to buy a player in the post that the club team needed is very important. This person should have much information about the club team that works in it and the entire player that the club team needed. For buying a player we have a knowledge base based on the condition of club team and the player features. Some of the researchers designed an Expert System for betting on football game [4]; prediction the result of games [5]; and rate to the skill of football player [6].

According to our knowledge no one designed Expert Systems for advising to buy a football player, so in this work, we will present a design of an Expert System for advising to buy a football player using Visual Prolog. We preset in Section 2 Advise to buy Knowledge, Section 3 the Function of the System, Section 4 Expert System, Section 5 User Interface, and in Section 6 Conclusions.

\section{Advice Knowledge}

The advice knowledge of specialized advisor is required for the development of an Expert System. This knowledge is collected through the creation of personal interview with football advisor. Then, a set of rules is created where each rule contains in IF part that has the symptoms and in THEN part that has the player that should be suggested. The inference engine is a mechanism through which rules are selected to be fired. It is based on a pattern matching algorithm whose main purpose is to asso- 
ciate the facts (input data) with applicable rules from the rule base. Finally, the players are suggested by the inference engine. This Expert System defined the symptoms for buying a player. The scope of our Expert System is the following features: post needed by club, money to pay, player age, contract time, player injury type, player defence type, player foot, body balance, stamina, height, technic, tenacity, responsibility, speed, pass, shot power, acceleration, teamwork, head ability, nationality, free kick accuracy, goal keeper skills, jump ability. All of these features have an importance degree. It means that for example the post needed by club feature is more important than player age and our system ask this feature before player age. For each post the Expert System asks a part of these features that are important. For example, if GK post (Goal Keeper) is selected, these features are asked: post needed by club, money to pay, player age, contract time, goal keeper skills, jump ability, height, body balance, stamina, responsibility, defence, shot power, injury, tenacity, nationality. Each of these features has some conditions that are explained in Table $\mathbf{1}$.

For each of features the user selects one of the conditions. Then, we have an importance factor ("Very high", "High", "Medium", "Low", and "Not important"). The user selects one of the $\mathrm{m}$ and it means that how much this feature is important for him. We define each of these importance factors as following Table 2.

For the first question the system asks post needed by club and you can select for example GK post and the importance factor "Very high". Then, you can set this condition in our system and the inference engine with these conditions that you are selected decides whom players suggest to you.

\section{The Function of the System}

The proposed system performs many functions. It will conclude the players based on answers of the user to specific question that the system asks the user. The questions provide the system for explanation for the symptoms of the suggested players that help the Expert System for advice to buy a player by inference engine. It stores the facts and the conclusion of the inference of the system, and the user, for each case, in database. It processes the database in order to extract rules, which complete the knowledge base.

\section{Expert System}

A literature review of the last decade for the recording of development methodologies of Expert Systems surveys and classifies these methodologies using six categories [7]. This Expert System use following categories:

- Rule-based systems;

- Knowledge-based systems;
Table 1. Features and its conditions.

\begin{tabular}{|c|c|}
\hline Feature & Condition \\
\hline $\begin{array}{l}\text { Post needed by } \\
\text { club }\end{array}$ & [“GK”, “DF”, “MF”, “FW”]. \\
\hline Money to pay & $\begin{array}{l}\left.\left.\text { [“(Less than } 2 \mathrm{M}^{1} \$\right) \text { ", “(2 M\$ and } 5 \mathrm{M} \$\right) \text { ", } \\
\text { "(5 M\$ and } 10 \mathrm{M} \$) \text { ", “(Up to } 10 \mathrm{M} \$) \text { ]. }\end{array}$ \\
\hline Player age & $\begin{array}{l}\text { [“(Less than 18)”, “(18 and 23)”, } \\
\text { "(23 and 30)”, “(Up to 30)”]. }\end{array}$ \\
\hline Contract time & [“1”, “2”, “3”, “4”, “5”]. \\
\hline Player injury type & $\begin{array}{l}\text { [“Very weak”, "Weak”, } \\
\text { "Medium”, "Strong”, "Very strong”]. }\end{array}$ \\
\hline $\begin{array}{l}\text { Player defence } \\
\text { type }\end{array}$ & $\begin{array}{l}\text { ["Very weak", "Weak", } \\
\text { "Medium”, “Strong”, "Very strong”]. }\end{array}$ \\
\hline Player foot & [“Left”, “Right”, “Both”]. \\
\hline Body balance & $\begin{array}{l}\text { [“Very weak”, "Weak”, } \\
\text { "Medium”, “Strong”, "Very strong”]. }\end{array}$ \\
\hline Stamina & $\begin{array}{l}\text { [“Very weak”, "Weak”, } \\
\text { "Medium”, “Strong”, "Very strong”]. }\end{array}$ \\
\hline Height & [“Short”, “Medium”, “Tall”, “Very tall”]. \\
\hline Technic & [“Bad”, “Medium”, “Good”, “Very good”]. \\
\hline Tenacity & [“Bad”, “Medium”, “Good”, "Very good”]. \\
\hline Responsibility & [“Bad”, “Medium”, “Good”, “Very good”]. \\
\hline Speed & $\begin{array}{l}\text { [“Very slow", “Slow”, } \\
\text { "Medium”, "Fast”, "Very fast”]. }\end{array}$ \\
\hline Pass & [“Bad”, “Medium”, “Good”, "Very good”]. \\
\hline Shot power & $\begin{array}{l}\text { ["Very weak”, “Weak”, } \\
\text { "Medium”, "Strong”, "Very strong”]. }\end{array}$ \\
\hline Acceleration & [“Bad”, “Medium”, “Good”, “Very good”]. \\
\hline Teamwork & [“Bad”, “Medium”, “Good”, “Very good”]. \\
\hline Head ability & [“Bad”, “Medium”, “Good”, “Very good”]. \\
\hline Nationality & $\begin{array}{l}\text { [“Iran”, “America ML”, } \\
\text { "Europe ML”, “Africa ML”, “Asia ML”]. }\end{array}$ \\
\hline Freekick accuracy & [“Bad”, “Medium”, “Good”, “Very good”]. \\
\hline Goal keeper skills & [“Bad”, “Medium”, “Good”, “Very good”]. \\
\hline Jump ability & [“Bad”, “Medium”, “Good”, “Very good”]. \\
\hline
\end{tabular}

Table 2. Importance factor and its percent.

\begin{tabular}{cc}
\hline Importance factor & Percent \\
\hline Very high & $100 \%$ \\
High & $0.75 \%$ \\
Medium & $0.5 \%$ \\
Low & $0.25 \%$ \\
Not important & $0.01 \%$ \\
\hline
\end{tabular}

- Intelligent agent (IA);

- Database methodology;

- Inference engine;

- System-user interaction.

The Expert System developed in this work consists of the user interface, the explanation facility, the knowledge base, and the inference engine. The structure of the Expert System is shown in Figure 1. 


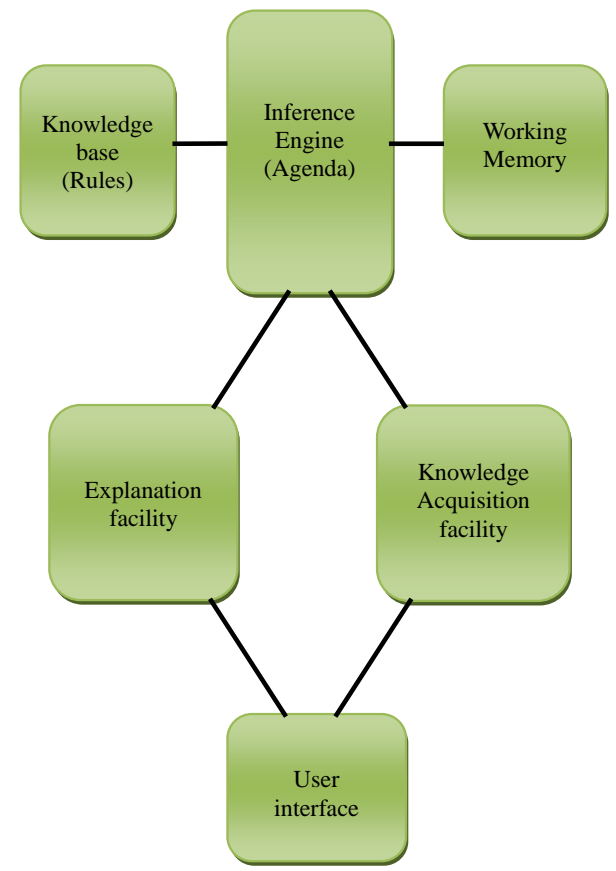

Figure 1. The structure of the expert system.

In the present article the problem of advice to buy a football player are implemented by methodology rule based systems [8]. One of the well-known methods of representation in the Expert System is prolog. Prolog is one of the principal languages used by researchers in Artificial Intelligence, with many applications developed in that field, especially in the form of Expert Systemsprograms that "reason out" the solution to complex problems using rules. You do not need to be an experienced programmer to learn Prolog [9]. Some initial familiarity with basic computing concepts such as program, variable, constant and function would make it easier to achieve, but paradoxically too much experience of writing programs in other languages may make the task harder-it may be necessary to unlearn bad habits of thinking learnt elsewhere. On our Expert System contains 120 rules. The system asks in each post max 15 questions. In each five question system can give some suggestions. This is because the user may not want to answer the all the questions and the questions on the first satisfies his conditions. Below we present the five rules for GK post that answers the user in five questions.

/*********************buy $5 \mathrm{GK}^{* * * * * * * * * * * * * * * * * * * * * /}$ buy5GK(Player,CFMain,Rate,RuleNum,Post,Salary,Age, Contract,GKSkills):(postrate(Player,Post,Rate1), salary(Player,Salary), age(Player,Age), contract(Player,Contract), gkskill(Player,GKSkills),
Rate=Rate1, RuleNum=“buy5GK, R1”, CFMain=1); (postrate(Player,Post,Rate1), salary(Player,Salary), age(Player,Age), contract(Player,Contract), not(gkskill(Player,GKSkills)), Rate=Rate1, RuleNum=“buy5GK,R2”, CFMain=0.8); (postrate(Player,Post,Rate1), salary(Player,Salary), age(Player,Age), not(contract(Player,Contract)), not(gkskill(Player,GKSkills)),

Rate=Rate1, RuleNum=“buy5GK,R3”, CFMain=0.6); (postrate(Player,Post,Rate1), salary(Player,Salary), not(age(Player,Age)), not(contract(Player,Contract)), not(gkskill(Player,GKSkills)), Rate=Rate1, RuleNum=“buy5GK,R4”, CFMain=0.4); (postrate(Player,Post,Rate1), not(salary(Player,Salary)), not(age(Player,Age)), not(contract(Player,Contract)), not(gkskill(Player,GKSkills)),

Rate=Rate1, RuleNum=“buy5GK,R5”, CFMain=0.2).

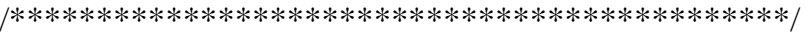

As shown in above each player has rate that is the skill of the player and each rule has CFMain that means the certain factor of rule. The final CF (Certain factor) shows to user is computed as follows:

If $\times 1$ with $\mathrm{CF} 1$ and $\times 2$ with $\mathrm{CF} 2$ then $\mathrm{H}$ with $\mathrm{CF}$,

$\mathrm{C}=\min (\mathrm{CF} 1, \mathrm{CF} 2)$,

CFFinal $=\mathrm{CF}^{*} \mathrm{C}$.

\section{User Interface}

Communication between the user and the system is done through the user interface which was implemented in English. The user interface has two parts: Question part and Advice part. In the Question part system ask question and you select your condition then with set condition button you set it. For each question that the user sees in the system he can see the "why condition" with click why button. In the Advice part for each five question that the 
user is answered, he can click on "Advice player" button and the system can suggest players for him. The system answers the player's name, rate (skill of player), CF and the fired rule. With the button "how" and "show rule" if you select a player and the click on "how" button the system shows you how answer this player and if you select the rule and the click on "show rule", the system shows you rule fired. The "system result" is shown in Figure 2.

\section{Conclusions}

The application of Expert System in advice to buy a player is very efficient. The proposed system can help club team to buy a good football player for its team. The system constitutes part of intelligent system of advising

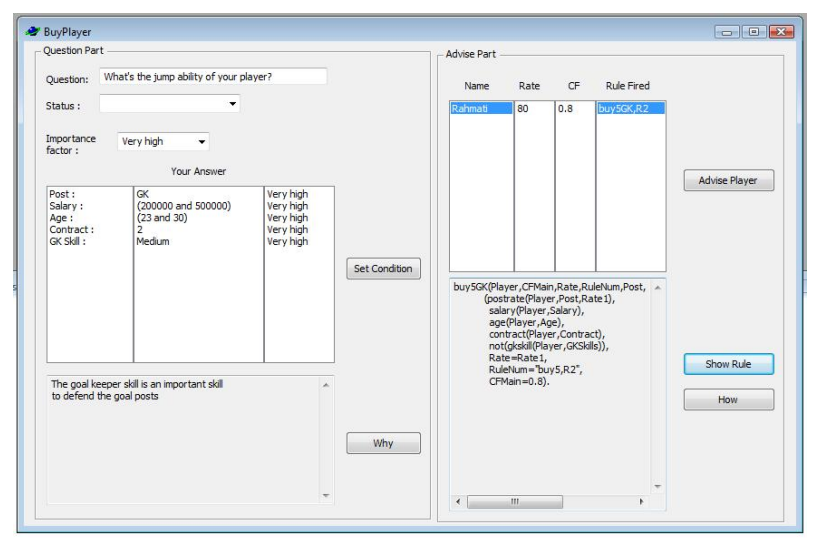

Figure 2. A sample of the system result.

Table 3. Comparison of expert system suggestions and advisors suggestions.

\begin{tabular}{|c|c|c|c|}
\hline $\begin{array}{c}\text { Post needed } \\
\text { by } \\
\text { club }\end{array}$ & $\begin{array}{c}\text { Advisor1 } \\
\text { suggestions }\end{array}$ & $\begin{array}{l}\text { Advisor2 } \\
\text { suggestions }\end{array}$ & $\begin{array}{c}\text { Our expert } \\
\text { system suggestions }\end{array}$ \\
\hline GK & $\begin{array}{l}\text { “Rahmati” } \\
\text { “Talebloo” }\end{array}$ & $\begin{array}{l}\text { “Rahmati” } \\
\text { “Talebloo” }\end{array}$ & $\begin{array}{l}\text { “Rahmati” } \\
\text { "Talebloo” }\end{array}$ \\
\hline CB & $\begin{array}{l}\text { "Hajsafi” } \\
\text { "Nosrati” } \\
\text { "Bengar” }\end{array}$ & $\begin{array}{l}\text { “Hajsafi” } \\
\text { "Ashjari” } \\
\text { "Nosrati” }\end{array}$ & $\begin{array}{l}\text { "Hajsafi” } \\
\text { "Nosrati” } \\
\text { "Bengar" } \\
\text { "Ashjari” }\end{array}$ \\
\hline $\mathrm{MF}$ & $\begin{array}{l}\text { “Karimi” } \\
\text { “Teymorian” } \\
\text { “Nekounam” } \\
\text { “Shojaei” }\end{array}$ & $\begin{array}{l}\text { “Karimi” } \\
\text { “Nekounam” } \\
\text { “Shojaei” }\end{array}$ & $\begin{array}{l}\text { “Karimi” } \\
\text { “Teymorian” } \\
\text { “Nekounam” } \\
\text { “Shojaei” } \\
\text { "Mobali” } \\
\text { “Jabbari” }\end{array}$ \\
\hline FW & $\begin{array}{l}\text { “Ansarifard” } \\
\text { “Norouzi”, } \\
\text { "Meydavoudi” }\end{array}$ & $\begin{array}{l}\text { “Ansarifard” } \\
\text { "Meydavoudi” }\end{array}$ & $\begin{array}{c}\text { “Ansarifard” } \\
\text { “Norouzi” } \\
\text { “Meydavoudi” } \\
\text { “Oladi” }\end{array}$ \\
\hline
\end{tabular}

to buy a football player. An initial evaluation of the Expert System was done by club team advisor and management. A number of them tested the system and gave us a positive feedback to develop this system. As you see in the Table 3, we compare our Expert System suggestions with two advisors of two club teams suggestions in the post that club teams needed with same questions that asked and same conditions that answered to the questions.

The Table 3 shows that our Expert System can suggest as well as the advisors and also can give more suggestions to the user. As future work we will constitute the Expert System to cover more information from other advisor and implemented it with big database of players.

\section{REFERENCES}

[1] B. G. Hope and R. H. Wild, “An Expert Support System for Service Quality Improvement," Proceedings of the Twenty-Seventh Annual Hawaii International Conference on System Science, Honolulu, 4-7 January 1994, pp. 183190. doi:10.1109/HICSS.1994.323353

[2] S. Azaab, S. A. Naser and O. Sulisel, "A Proposed Expert System for Selecting Exploratory Factor Analysis Procedures," Journal of the College of Education, Vol. 4, No. 2, 2000, pp. 9-26.

[3] E. Turban, "Expert System and Applied Artificial Intelligence,” Macmillan Publishing Company, New York, 1992.

[4] S. Josef, "NFL Betting-Football Betting System for Big Winners,” Ezine Articles, 2010. http://ezinearticles.com/?NFL-Betting---Football-BettingSystem-for-Big-Winners\&id=5860261

[5] B. Min and J. Kim, "A Compound Framework for Sports Prediction: The Case Study of Football," KnowledgeBased Systems or Expert Systems with Applications, Vol. 21, No. 7, 2007, pp. 551-562.

[6] R. Aughey, “Australian Football Player Work Rate,” International Journal of Sports Physiology and Performance, Vol. 5, No. 3, 2010, pp. 394-405.

[7] S. H. Liao, "Methodologies and Applications-A Decade Review from 1995 to 2004,” Expert Systems with Applications, Vol. 28, No. 1, 2005, pp. 93-103. doi:10.1016/j.eswa.2004.08.003

[8] H. Monsef, A. M. Ranjbar and S. Jadid, "A Rule-Based Expert System for Power System Fault Diagnosis,” Proceedings of 9th International Power System Conference, St. Petersburg, July 1994, p. 375.

[9] T. W. de Boer, “A Beginner's Guide to Visual Prolog," 2009. download.pdc.dk/vip/71/deBoer-BeginnersGuide.pdf 